\title{
RTP801 Is Elevated in Parkinson Brain Substantia Nigral Neurons and Mediates Death in Cellular Models of Parkinson's Disease by a Mechanism Involving Mammalian Target of Rapamycin Inactivation
}

\author{
Cristina Malagelada, ${ }^{1}$ Elizabeth J. Ryu, ${ }^{2}$ Subhas C. Biswas, ${ }^{1}$ Vernice Jackson-Lewis, ${ }^{3}$ and Lloyd A. Greene ${ }^{1}$ \\ ${ }^{1}$ Department of Pathology and Center for Neurobiology and Behavior, ${ }^{2}$ Institute of Human Nutrition, and ${ }^{3}$ Department of Neurology, Columbia University, \\ New York, New York 10032
}

\begin{abstract}
The molecules underlying neuron loss in Parkinson's disease (PD) are essentially unknown, and current therapies focus on diminishing symptoms rather than preventing neuron death. We identified RTP801 as a gene whose transcripts were highly induced in a cellular model of PD in which death of neuronal catecholaminergic PC12 cells was triggered by the PD mimetic 6-0HDA. Here, we find that RTP801 protein is also induced in this and additional cellular and animal PD models. To assess the relevance of these observations to PD, we used immunohistochemistry to compare RTP801 expression in postmortem brains from PD and control patients. For all PD brains examined, expression was highly elevated within neuromelanin-containing neurons of the substantia nigra but not in cerebellar neurons. Evaluation of the potential role of RTP801 induction in our cellular model revealed that RTP801 overexpression is sufficient to promote death but does not further elevate death caused by 6-OHDA. Furthermore, RTP801 induction is requisite for death in our cellular PD models and in 6-OHDA-treated cultured sympathetic neurons in that its knockdown by short hairpin RNAs (shRNAs) is protective. The mechanism by which 6-OHDA and RTP801 induce neuron death appears to involve repression of mammalian target of rapamycin (mTOR) kinase activity, and such death is inhibited by shRNAs targeting TSC2 (tuberous sclerosis complex), a protein with which RTP801 interacts to block mTOR activation. Our findings thus suggest that the elevation of RTP801 we detect in PD substantia nigral neurons may mediate their degeneration and death and that RTP801 and its signaling cascade may be novel potential therapeutic targets for the disease.
\end{abstract}

Key words: Parkinson; 6-hydroxydopamine; RTP801; neuronal apoptosis; REDD1; PC12 cells

\section{Introduction}

Parkinson's disease (PD) is characterized by progressive loss of neuronal populations, including those of the substantia nigra pars compacta $(\mathrm{SNpc})$. The basis for such degeneration are presently unknown, and current therapies offer symptomatic treatment rather than prevention of neuron death (Hughes et al., 1993; Fahn, 1998). Identification of novel proteins involved in the pathophysiology of PD thus provides potential targets for therapeutic intervention.

Observations that PD-like syndromes and selective death of substantia nigral neurons are triggered by rotenone (Gorell et al.,

Received Sept. 27, 2005; accepted Aug. 15, 2006.

This work was supported in part by grants from the National Institutes of Health-National Institute of Neurological Disorders and Stroke and the Parkinson's Disease Foundation. We thank Drs. Jean-Paul Vonsattel, Serge Przedborski, and Miquel Vila for aid in provision of tissue sections and Drs. Robert Burke, Peter Canoll, Serge Przedborski, Elena Ribé, and Miguel López-Toledano for helpful discussions.

Correspondence should be addressed to Dr. Cristina Malagelada, Department of Pathology, Columbia University College of Physicians and Surgeons, 630 West 168th Street, New York, NY 10032. E-mail: cm2273@columbia.edu.

E. J. Ryu's present address: Department of Psychiatry, Washington University School of Medicine, Box 8118, 660 South Euclid Avenue, St. Louis, M0 63110-1093.

DOI:10.1523/JNEUROSCI.3292-06.2006

Copyright $\odot 2006$ Society for Neuroscience $\quad$ 0270-6474/06/269996-10\$15.00/0
1998; Sherer et al., 2003), 1-methyl-4-phenyl-1,2,3,6tetrahydropyridine (MPTP) (Thoenen and Tranzer, 1968; Davis et al., 1979), and 6-OHDA (Thoenen and Tranzer, 1968) support their use to model PD in vivo and in vitro. Although these toxins have limitations, their selective destruction of catecholaminergic neurons and promotion of cellular stress by inhibition of mitochondrial complex I and impairment of electron transport (which appear highly relevant to PD) (Blum et al., 2001; Dawson and Dawson, 2003; Beal, 2004; Tretter et al., 2004) make them valuable tools for studying PD-related neuron death mechanisms (Dauer and Przedborski, 2003)

Neuron death in many instances, including PD models, requires changes in gene expression. We previously used serial analysis of gene expression (SAGE) to detect regulated genes in a cellular PD model (Ryu et al., 2002, 2005). The intention was to identify genes with previously unrecognized roles in promoting neuron degeneration in PD. Neuronal [nerve growth factor (NGF)-treated] PC12 cells were exposed to 6-OHDA for $8 \mathrm{~h}$ (a time before overt signs of death and sufficient for transcriptional responses), and their transcriptome was compared with that of controls. Neuronal PC12 cells were used because these are catecholaminergic, resemble sympathetic neurons (a population af- 
fected in PD), and have well characterized 6-OHDA responses and transcriptomes (Walkinshaw and Waters, 1994; Blum et al., 1997; Ryu et al., 2002, 2005)

Of $\sim 1200$ significantly regulated transcripts detected, the most induced (97-fold) encoded the recently described RTP801/ Redd1/dexamethasone induced gene 2 (Ellisen et al., 2002; Shoshani et al., 2002; Wang et al., 2003). RTP801 is upregulated by stresses, including DNA damage, oxidative stress, hypoxia, and energy depletion (Ellisen et al., 2002; Shoshani et al., 2002; Frolov et al., 2003; Sofer et al., 2005). Among its actions, it may either cause or prevent death, depending on cell type and conditions. Of relevance, RTP801 overexpression protected non-neuronally differentiated PC12 cells from death induced by hypoxia or $\mathrm{H}_{2} \mathrm{O}_{2}$, whereas it caused death of neuronally differentiated PC12 cells and increased their sensitivity to oxidative stress and ischemia (Shoshani et al., 2002). How RTP801 triggers such different context-dependent responses is unknown. Recent studies in transformed cells indicate that RTP801 suppresses activation of mammalian target of rapamycin (mTOR) kinase by the G-protein Rheb and does so through interaction with the tuberous sclerosis complex (TSC) (Brugarolas et al., 2004; Corradetti et al., 2005).

Here, we explore the role of RTP801 in neuron death associated with PD. We find that RTP801 is elevated in substantia nigral neurons of both MPTP-treated mice and PD patients, is essential for death in cellular models of PD, and induces neuron death by a mechanism involving repression of $\mathrm{mTOR}$ kinase activity.

\section{Materials and Methods}

Antibodies, plasmids, and materials. Anti-RTP801 antiserum and monoclonal anti-tyrosine hydroxylase $(\mathrm{TH})$ were purchased from Chemicon (Temecula, CA). Anti-Redd1/RTP801(N-20), anti-TSC2, and antiextracellular signal-regulated kinase 1 (ERK1) antibodies were obtained from Santa Cruz Biotechnology (Santa Cruz, CA). Anti-V5 antibody was from Invitrogen (Carlsbad, CA). Anti-phospho-Ser371 p70S6K1, antiphospho-mTOR (Ser2448) (49F9), rabbit monoclonal antibody (IHC Specific), and anti-p70S6K1 were purchased from Cell Signaling Technology (Beverly, MA). Anti-horseradish peroxidase-, FITC-, or tetramethylrhodamine isothiocyanate-conjugated secondary antibodies were obtained from Pierce (Rockford, IL) and Jackson ImmunoResearch (West Grove, PA). RTP801 constructs were generated by PCR cloning (RTP801 forward, 5'-GAATTCGAACCATGCCTAGCCTTTGGGATCG-3'; RTP801 reverse, 5'-GTCGACTCAACACTCTTCAATGAGCA$3^{\prime}$ ) from a cDNA library derived from neuronal PC12 cells and ligated to the phosphorylated camelpox virus strain (pCMS)-enhanced green fluorescent protein (eGFP) vector or the pcDNA3-V5 vector (Invitrogen). All newly made constructs were verified by DNA sequencing. 6-OHDA and MPTP-HCl were purchased from Sigma (St. Louis, MO), and 1-methyl-4-phenylpyridinium $(\mathrm{MPP}+)$ and rotenone were obtained from Calbiochem (San Diego, CA).

Cell culture. PC12 cells were cultured and treated with NGF as described previously (Greene and Tischler, 1976; Yan and Greene, 1998). For NGF treatment, the cells were cultured in RPMI 1640 medium (Cellgro, Herndon, VA) supplemented with $1 \%$ horse serum, penicillin/streptomycin, and $50 \mathrm{ng} / \mathrm{ml}$ recombinant human NGF (a kind gift from Genentech, South San Francisco, CA) for 8-10 d. Medium was changed every other day and immediately before treatments. 6-OHDA, MPP +, and rotenone were prepared before use in $10 \mathrm{~mm}$ stocks and diluted in medium to the indicated final concentrations. NGF withdrawal was performed as described previously (Rukenstein et al., 1991). Neonatal rat superior cervical ganglion (SCG) sympathetic neurons were cultured as described previously (Troy et al., 2000; Ryu et al., 2002). Treatments with 6-OHDA and NGF withdrawal were performed at day 7 in vitro, and cell viability was assessed 24 and $48 \mathrm{~h}$ later, respectively. Values represent the mean \pm SEM of at least three different experiments.

Survival assay. Neuronal PC12 cells cultured in 24-well plates were treated as described with 6-OHDA, MPP+, rotenone, or $\mathrm{H}_{2} \mathrm{O}_{2}$ or subjected to NGF deprivation at days 7-9. At $24 \mathrm{~h}$ later, cells were lysed and viable nuclei were counted under the microscope in a Neubauer chamber as described previously (Rukenstein et al., 1991). Cell survival was expressed as the percentage of viable cells compared with sister control cultures. For transfection experiments, strips or whole wells were evaluated for numbers of surviving transfected cells as described previously (Xu et al., 2001; Biswas et al., 2005). Values represent the mean \pm SEM of at least three different experiments, using at least three wells per condition in each independent experiment.

Reverse transcription-PCR. Each sample of total RNA was isolated using Tri reagent (Molecular Research Center, Cincinnati, $\mathrm{OH}$ ) from one well of six-well plates of neuronal PC12 cells treated or not with 6-OHDA for different periods of time. Specific primers used for PCR analyses were as follows: RTP801 reverse primer, 5' -GAATTCGAACCATGCCTAGCCTTTGGGATCG-3'; RTP801 forward primer, 5'-GTCGACTCAACACTCTTCAATGAGCA-3'; $\alpha$-tubulin forward primer, $5^{\prime}$-ATGAGGCCATCTATGACATC- $3^{\prime}$; and $\alpha$-tubulin reverse primer, $5^{\prime}$ TCCACAAACTGGATGGTAC- $3^{\prime}$. PCR conditions used were $95^{\circ} \mathrm{C}$ (for $30 \mathrm{~s}$ ), $50^{\circ} \mathrm{C}$ (for $1 \mathrm{~min}$ ), and $72^{\circ} \mathrm{C}$ (for $45 \mathrm{~s}$ ) for 35 cycles in PCR buffer (Ryu et al., 2002) containing a final concentration of $16.6 \mathrm{~mm}$ ammonium sulfate, $67 \mathrm{~mm}$ Tris, $\mathrm{pH} 8.8$, $6.7 \mathrm{~mm}$ magnesium chloride, $0.6 \mathrm{~mm}$ dNTP, $10 \mathrm{~mm} \beta$-mercaptoethanol plus 6\% DMSO, $0.1 \mu \mathrm{m}$ forward and reverse primers, and $2.5 \mathrm{U}$ of platinum TaqDNA polymerase (Invitrogen). The amount of cDNA template used for each PCR analysis was adjusted to have the same levels of $\alpha$-tubulin products among all samples. PCR products were resolved on an agarose gel and photographed.

Short hairpin RNA production. Three different RTP801 short hairpin RNA (shRNA) and two different TSC2 shRNA were prepared in pSIREN vector by using BD KnockOut RNAi systems according to the instructions of the manufacturer (BD Biosciences, San Jose, CA) based on the following sequences: for RTP801, A, 5' -AAG ACT CCT CAT ACC TGG ATG-3', targeting mouse and rat RTP801 sequence; B, 5' ${ }^{\prime}$-AAC CTG ATG CAG CTG CTG CAG-3', targeting human, mouse, and rat RTP801 sequence; C, 5'-AAG AGC TGC CAT AGT GTG GCT-3', targeting mouse and rat RTP801 sequence; for TSC2, A, 5' -AAC ATG TGC CGT ATC ATG GAG-3'; B, 5' -AAG ACG GCA GTC CTC GGG CTC-3'. As indicated by BLAST (basic local alignment search tool) searches, none of these sequences showed significant homology with other rat sequences. Because of their low transfection efficiency and high background staining observed with anti-RTP801, we were unable to directly assess the efficacy of our shRNA in neuronal PC12 cells. The efficacy of the action of the RTP801 shRNAs was therefore assessed by cotransfecting HEK293 cells with pSIREN shRTP801 and pcDNA3.1/V5-His RTP801. Sister cultures were cotransfected with pSIREN shLuciferase and pcDNA3.1/V5-His RTP801 as a control. After $48 \mathrm{~h}$, cell extracts were collected and analyzed by Western blot with anti-V5 mouse monoclonal antibody (Invitrogen). The efficacy of TSC2 shRNA was tested by immunocytochemistry with an antibody against TSC2 in transfected neuronal PC12 cells with pSIREN shLuciferase or pSIREN shTSC2.

Transfection. Neuronal PC12 cells and rat sympathetic neurons were transfected with Lipofectamine 2000 (Invitrogen) according to the instructions of the manufacturer. At $48 \mathrm{~h}$ after transfection, cells were treated with 6-OHDA, $\mathrm{MPP}+$, rotenone, $\mathrm{H}_{2} \mathrm{O}_{2}$, or tunicamycin or were deprived of NGF. At 24 or $48 \mathrm{~h}$ after the treatments, viable transfected (as judged by expression of fluorophore) neuronal PC12 or sympathetic neurons were scored by strip counting or whole-well counting, respectively, under an epifluorescence microscope (Xu et al., 2001).

Western blot analysis. Whole-cell extracts were collected in lysis buffer (Cell Signaling Technology), sonicated, and centrifuged at $14,000 \times g$. Protein concentration was determined with Bradford reagent (Bio-Rad, Hercules, CA), and $35 \mu \mathrm{g}$ of protein of each condition was resolved on NuPAGE precast $4-12 \%$ Bis-Tris gradient gels (Invitrogen). Protein was transferred to a nitrocellulose membrane and probed with anti-RTP801 chicken antibody at 1:1000 or anti-ERK at 1:5000. Goat anti-rabbit or goat anti-chicken horseradish peroxidase-conjugated secondary antibodies were incubated $1 \mathrm{~h}$ at room temperature, signal was detected with Supersignal West dura extended duration substrate (Pierce), and 
membranes were exposed to BioMax MR film (Eastman Kodak, Rochester, NY).

Animals and treatment. Ten-week-old wild-type male C57BL mice (Charles River Laboratories, Wilmington, MA) received four injections of $20 \mathrm{mg} / \mathrm{kg}$ MPTP (free base) intraperitoneally in $1 \mathrm{~d}$, at $2 \mathrm{~h}$ intervals (20 $\mathrm{mg} / \mathrm{kg}$ free base; Sigma), and were killed at $24 \mathrm{~h}$ after. Control mice received saline injections only ( $n=2$ mice per treatment).

Immunohistochemistry in mouse sections. Sections of $20 \mu \mathrm{m}$ from saline-injected $(n=2)$ or MPTP-injected $(n=2)$ mice were blocked with $10 \%$ FBS, $1 \%$ BSA, and $0.3 \%$ Triton X-100 in PBS for 30 min. Primary antibodies anti-tyrosine hydroxylase (Chemicon) and anti-RTP801 (Santa Cruz Biotechnology) were incubated overnight in the blocking buffer. Sections were then washed in PBS and incubated with secondary antibodies for $2 \mathrm{~h}$ at room temperature. Sections were washed in PBS and mounted with mounting media on slides for their observation under fluorescence microscopy.

Immunohistochemistry in human sections. Sections of PD and non-PD substantia nigra and cerebellum were obtained from the New York Brain Bank at Columbia University with the aid of Drs. Jean-Paul Vonsattel, Serge Przedborski, and Miquel Vila. Paraffin-embedded sections were heated for $1 \mathrm{~h}$ at $65^{\circ} \mathrm{C}$ and dewaxed in xylene. Rehydration was performed by incubating the slides in an ethanol series (100, 75, and 50\%). Sections were incubated in $1 \% \mathrm{H}_{2} \mathrm{O}_{2}$ at room temperature for $30 \mathrm{~min}$ to block nonspecific peroxidase activity, and then antigen was retrieved in $10 \mathrm{~mm}$ citrate buffer, $\mathrm{pH} 6.0$, in a microwave oven at $98^{\circ} \mathrm{C}$ for $10 \mathrm{~min}$. Sections were then washed with TBS- $0.5 \%$ Triton X-100 (TBST), blocked first with avidin/biotin solution (Vector Laboratories, Burlingame, CA), and subsequently blocked in $0.1 \%$ BSA-TBST for $1 \mathrm{~h}$ at room temperature. They were then incubated with chicken anti-RTP801 primary antiserum overnight at $4^{\circ} \mathrm{C}$ and with biotinylated secondary antibody for $1 \mathrm{~h}$ at $37^{\circ} \mathrm{C}$. Sections were next incubated in ready-to-use $\mathrm{ABC}$ complex solution (Vector Laboratories) at room temperature for $30 \mathrm{~min}$, and then SG substrate (Vector Laboratories) was added. Sections were washed, mounted with mounting media, and observed under the microscope.

Immunocytochemistry. Cells were fixed in $4 \%$ formaldehyde in PBS for 20 min at room temperature. After washing with PBS, cells were incubated with the blocking solution (5\% goat serum in PBS) for $1 \mathrm{~h}$ at room temperature and then incubated overnight with the primary antibody, diluted also in 5\% goat serum in PBS. Cells were washed three times in PBS and incubated for $1 \mathrm{~h}$ with a secondary antibody. After washing in PBS, cells were stained with Hoechst 33342 and mounted with mounting medium (Vector Laboratories). For the experiment scoring phosphomTOR-positive cells in ectopically expressed RTP801 conditions, cells were fixed for immunostaining $24 \mathrm{~h}$ after transfection.

Statistics. All experiments were performed at least in triplicate, and results are reported as means \pm SEM. Student's $t$ test was performed as unpaired, two-tailed sets of arrays and presented as $p$ values.

\section{Results \\ 6-OHDA induces both RTP801 gene transcription and protein expression}

Previous SAGE results showed that the most highly upregulated transcript in 6-OHDA-treated neuronal PC12 cells is RTP801. This induction was also detected by Northern blotting (Ryu et al., 2005). We therefore first determined whether this response could be confirmed by an alternative approach and whether it was also reflected at the level of protein expression. Neuronal PC12 cells were exposed to a concentration of 6-OHDA that induced $\sim 40-$ $50 \%$ cell death by $24 \mathrm{~h}$ (Fig. $1 \mathrm{~A}$ ) and were analyzed for RTP801 mRNA and protein by reverse transcription (RT)-PCR and Western immunoblotting, respectively. RTP801 transcripts were detectably upregulated by $8 \mathrm{~h}$ of 6-OHDA exposure and were strongly induced by $24 \mathrm{~h}$ (Fig. $1 \mathrm{~B}$ ). Similarly, RTP801 protein levels were induced by $8 \mathrm{~h}$ of 6-OHDA exposure (Fig. 1C).

We next determined whether RTP801 was upregulated in two additional cellular models of PD. Neuronal PC12 cells were
A

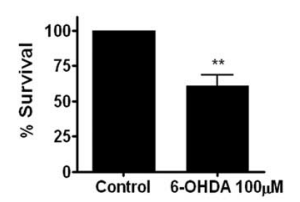

B

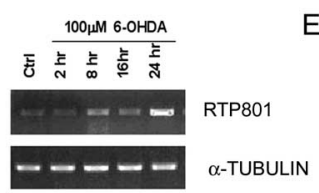

E
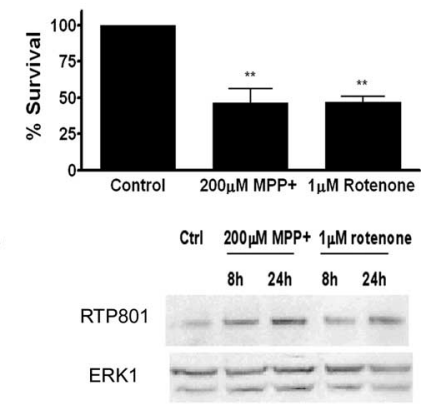

C

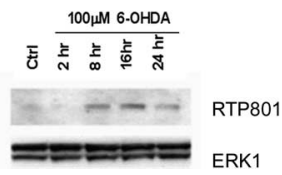

Figure 1. Induction of RTP801 in cellular models of PD. $A$, Quantitation of neuronal $P C 12$ cell survival after exposure to $100 \mu \mathrm{m} 6-0 \mathrm{HDA}$ for $24 \mathrm{~h} .{ }^{* *} p<0.001$ compared with control. $\boldsymbol{B}$, Induction of RTP801 transcripts in response to 6-OHDA. Total RNA was extracted from neuronal PC12 cells treated with $100 \mu \mathrm{m}$ 6-OHDA for different periods of time as indicated and used for RT-PCR with specific primers for RTP801 and $\alpha$-tubulin. PCR products were resolved on a $5 \%$ agarose gel and stained with ethidium bromide. C, Western immunoblot analysis of RTP801 expression at different time points after treating neuronal PC12 cells with $100 \mu \mathrm{m} 6-0 \mathrm{HDA}$. The membrane was reprobed with anti-ERK1 antibody (bottom) as a loading control. D, Quantitation of neuronal PC12 cell survival after $200 \mu \mathrm{M}$ MPP + and $1 \mu \mathrm{m}$ rotenone exposure for $24 \mathrm{~h}$. ${ }^{* *} p<0.001$ compared with control. E, Western immunoblot analysis of RTP801 expression at different time points after treatment of neuronal PC12 cells with $200 \mu \mathrm{M}$ MPP + or $1 \mu \mathrm{M}$ rotenone for 8 or $24 \mathrm{~h}$ (top). The bottom shows the same blot probed for ERK1 as a loading control. Ctrl, Control.

treated with MPP + or rotenone, neurotoxins that selectively destroy dopaminergic neurons in vitro and in vivo, in part by impairing the mitochondrial electron transport chain. Western immunoblotting revealed that RTP801 protein was induced under conditions in which each toxin causes $\sim 50 \%$ cell death by $24 \mathrm{~h}$ (Fig. 1D,E). Together, these results indicate that RTP801 is upregulated at both the transcriptional and protein expression levels in neuronal cells in multiple cellular models of PD.

The induction of RTP801 in cellular PD models led us to next examine whether this protein is upregulated in additional paradigms of neuronal apoptosis. Neuronal PC12 cells were subjected to $100 \mu \mathrm{M} \mathrm{H}_{2} \mathrm{O}_{2}$ (an inducer of oxidative stress), $40 \mu \mathrm{M}$ camptothecin (a DNA damaging agent), $10 \mu \mathrm{M}$ tunicamycin (an inducer of endoplasmic reticulum stress and the unfolded protein response, both of which occur in response to 6-OHDA) (Ryu et al., 2002), or NGF deprivation. Under the conditions of our experiments, $40-80 \%$ of the cells died by $24 \mathrm{~h}$ (Fig. $2 \mathrm{~B}$ ). At $16 \mathrm{~h}$, only the peroxide treatment induced RTP801 to the same level as 6-OHDA, with a lesser effect noted with camptothecin. The peroxide finding is consistent with previous studies in which this agent induced RTP801 in human neuroblastoma cells (Kim et al., 2003). There was no induction with NGF deprivation or tunicamycin treatment (Fig. 2A). Of relevance, like peroxide and camptothecin, the PD mimetic toxins also promote oxidative stress and DNA damage.

\section{RTP801 is induced in the mouse MPTP PD model}

Because of the induction of RTP801 in cellular models of PD, we determined whether RTP801 was also induced in an animal model of PD, namely the mouse MPTP model. Animals were subjected to intraperitoneal injection of MPTP or saline control and killed $24 \mathrm{~h}$ later, a time when cell death has begun (JacksonLewis et al., 1995). Coronal sections of brains from both treat- 
A

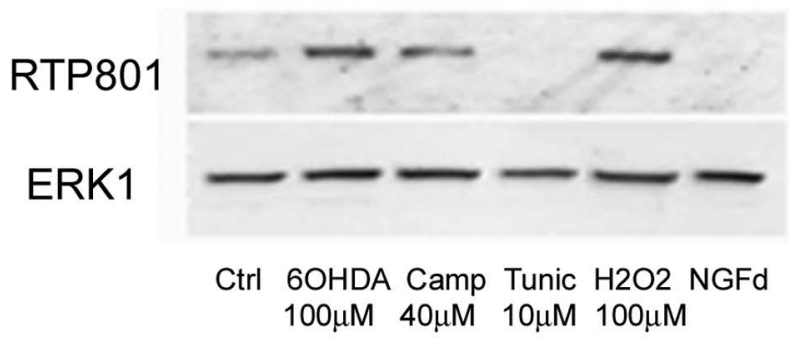

B

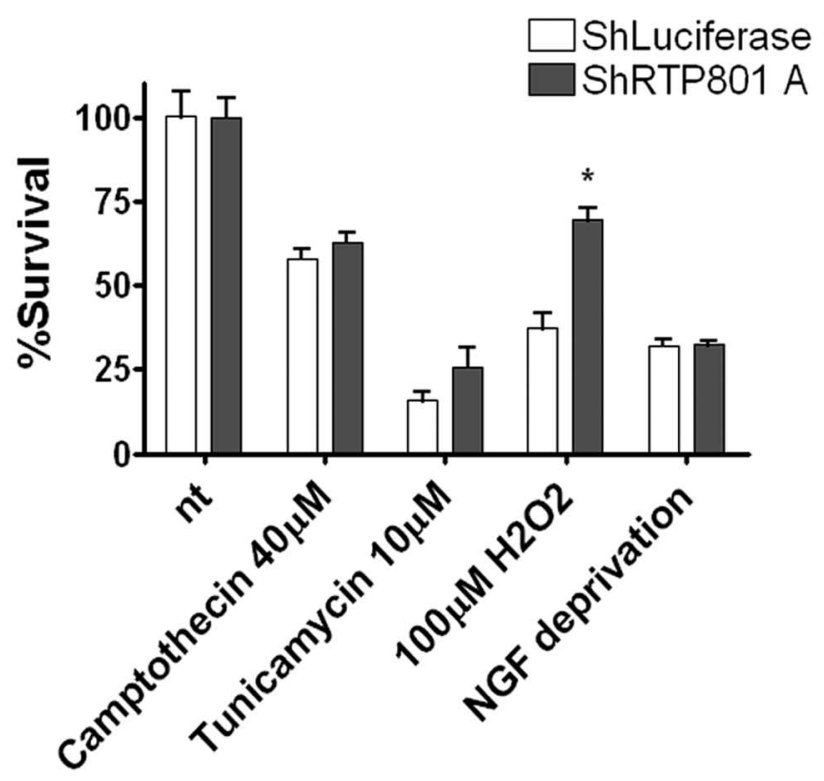

Figure 2. Regulation and role of RTP801 in various cell death models. $A$, RTP801 Western immunoblot analysis of neuron-like PC12 cell treated for $16 \mathrm{~h}$ with $100 \mu \mathrm{M} \mathrm{6-0HDA,} 40 \mu \mathrm{M}$ camptothecin (Camp), $10 \mu$ m tunicamycin (Tunic), or $100 \mu \mathrm{M} \mathrm{H}_{2} \mathrm{O}_{2}$ or deprived of NGF (NGFd). The bottom shows an ERK1 loading control. Similar results were achieved in three independent experiments. Ctrl, Control. B, Effect of RTP801 knockdown in various cell death paradigms. Neuronal PC12 cells were transfected with a specific shRNA for RTP801 (pSIREN-shRTP801A) and, in parallel as a control, with a shRNA against firefly luciferase. Two days later, cultures were then exposed to $40 \mu \mathrm{m}$ camptothecin, $10 \mu \mathrm{m}$ tunicamycin, or $100 \mu \mathrm{M} \mathrm{H}_{2} \mathrm{O}_{2}$ or to NGF deprivation. Cell survival was assessed by counting surviving transfected cells under fluorescence microscopy after an additional $24 \mathrm{~h}$. Results are expressed as mean \pm SEM of at least three independent experiments with triplicates in each condition. ${ }^{*} p<0.03$, significantly different from shLuciferase-transfected cells. nt, Not treated.

ments were coimmunostained for $\mathrm{TH}$ (a marker for catecholaminergic neurons) and RTP801. Sections of the SN of MPTP-treated animals showed an intense staining for RTP801, whereas those from control animals showed a much lower basal level of signal (Fig. 3). Many of the cells with high staining for RTP801 in MPTP-treated animals were also positive for TH, although nearby cells in the same section were also observed that were positive for RTP801 but TH negative. The latter most likely reflect the previously reported (Jackson-Lewis et al., 1995) rapid loss of TH from SN neurons in MPTP-treated animals. There was no evident MPTP-promoted change in RTP801 immunostaining in areas outside of the substantia nigra such as the cerebral cortex.
The efficacy of the RTP801 antiserum (Santa Cruz Biotechnology) was verified in mouse CAD cells, transfected with a control or two different shRNAs targeting endogenous mouse RTP801 (shRTP801A and shRTP801C). In both cases, the RTP801-targeted shRNAs substantially decreased expression of the endogenous RTP801 band as detected by Western immunoblotting (supplemental Fig. 1, available at www.jneurosci.org as supplemental material). In addition, immunostaining was absent in the mouse sections when the primary antiserum was omitted, and staining with single antisera confirmed the absence of bleedover between channels.

\section{RTP801 is highly expressed in human Parkinson's disease substantia nigra neurons}

Because of the induction of RTP801 in both cellular and animal models of $\mathrm{PD}$, we also examined the expression of this protein in sections of human substantia nigra derived from four control and four postmortem PD brains. A major feature of PD is specific degeneration and loss of dopaminergic neuromelanin-positive neurons in the SNpc (Hughes et al., 1993). Because neuromelanin is visible under bright-field microscopy because of its brown color, we could readily identify this neuronal type without the need for other specific markers. Immunohistochemical staining with antiserum generated against human RTP801 (Chemicon) revealed little or no detectable specific expression of RTP801 in neuromelanin-positive neurons in the $\mathrm{SN}$ of sections derived from control brains (Fig. 4A). In contrast, in sections of SN from all four PD brains, we observed that neuromelanin-positive neurons were specifically and strongly stained for RTP801 (Fig. 4B, blue stain) (data not shown). We did not detect RTP801-positive staining in neuromelanin-negative cells that appeared to lie outside the $\mathrm{SN}$ in the same sections from control and PD brains (data not shown). To further assess the specificity of RTP801 expression, we also immunostained sections of cerebellum from the same control and PD patients. This area of the brain does not appear to be affected in PD. No staining was observed in either PD or control cases (Fig. 4, cerebellum). In addition, no staining was observed in sections of SN from PD patients when the antiserum was preabsorbed with RTP801 fusion protein (Fig. 4, PD: protein absorption). Moreover, recognition of endogenous RTP801 by the same antiserum in HEK293 cells was markedly decreased by an shRNA (shRTP-B) that targets human (as well as mouse and rat) RTP801 but not by one targeting only mouse and rat RTP801 (shRTP-C) (supplemental Fig. 1, available at www. jneurosci.org as supplemental material) These results indicate that there is an increase of RTP801 expression that is a specific feature of neuromelanin-positive neurons in cases of PD.

\section{RTP801 overexpression induces neuronal PC12 cell death}

To elucidate the potential role of RTP801 in PD, we first monitored the effect of forced RTP801 expression on survival of neuronal PC12 cells. For this purpose, cultures were transiently transfected with pCMS-eGFP vector as a control or with pCMSRTP801 eGFP, and 24 and $48 \mathrm{~h}$ later the numbers of surviving transfected [eGFP-positive $\left(\mathrm{eGFP}^{+}\right)$] cells were assessed (Fig. 5). Consistent with a previous report (Shoshani et al., 2002), we observed that overexpression of RTP801 led to a loss of 50\% of transfected cells after $24 \mathrm{~h}$ and that this percentage did not increase by $48 \mathrm{~h}$. It was reported previously that RTP801 overexpression sensitizes neuronal cells to die in situations such as ischemic injury or oxidative stress (Shoshani et al., 2002). However, when we exposed RTP801 overexpressing cells to $100 \mu \mathrm{M}$ 6-OHDA, no additional cell death was observed, even after $48 \mathrm{~h}$. 
These results indicate that overexpression of RTP801 promotes death of otherwise unstressed neuronal cells but does not enhance death of 6-OHDA-treated cells in which endogenous RTP801 is already induced.

\section{RTP801 upregulation mediates cell} death in cellular models of PD

To further study the role of RTP801 upregulation in cellular models of $\mathrm{PD}$, we used shRNA [short hairpin RTP801A] designed to knock down expression of mouse and rat RTP801. Western immunoblots prepared from extracts of HEK293 cells cotransfected with pcDNA3.1/V5-His rRTP801 and either pSIREN-shRTP801A or, as a control, pSIREN-shLuciferase confirmed the efficacy of the shRNA in knocking down rRTP801 expression (Fig. 6A). Next, neuronal PC12 cells were transiently transfected with pSIREN-shLuciferase or pSIREN-shRTP801A, and, $48 \mathrm{~h}$ later, the cultures were exposed to 6-OHDA, $\mathrm{MPP}+$, or rotenone for an additional 1 or 2 d. Counts of surviving transfected $\left(\right.$ DsRed $^{+}$) cells revealed clear cellular protection by the RTP801 shRNA in all three models at $24 \mathrm{~h}$ (Fig. 6B) and in the 6-OHDA and MPP + models at $48 \mathrm{~h}$ (Fig. $6 C)$ of treatment. In contrast to cells transfected with the control shRNA, which were often degenerated and lacking neurites after exposure to 6-OHDA, those expressing shRTP801A generally appeared to be healthy and to possess neurites (Fig. 7). To verify the specificity of the shRNA, we prepared two additional shRTP801 constructs $(B, C)$ targeted against independent regions of the transcript (see Materials and Methods). These were equally effective as shRTP801A in reducing RTP801 expression and in protecting cells from 6-OHDA (Fig. 6A) (supplemental Fig. 1, available at www.jneurosci.org as supplemental material).

We also compared the effect of shRTP801A on survival of cells subjected to 6-OHDA, camptothecin, tunicamycin, or $\mathrm{H}_{2} \mathrm{O}_{2}$ exposure or to NGF deprivation. Significant protection was observed only in the cases of 6-OHDA and $\mathrm{H}_{2} \mathrm{O}_{2}$ treatment (Fig. 2B). Similar results were achieved with shRTP801B (data not shown). Thus, RTP801 does not appear to be involved in all paradigms of neuronal death.

To extend our findings with neuronal PC12 cells to primary neurons, cultures of rat superior cervical ganglion sympathetic neurons were transfected with pSIRENshRTP801A or pSIREN-shLuciferase and

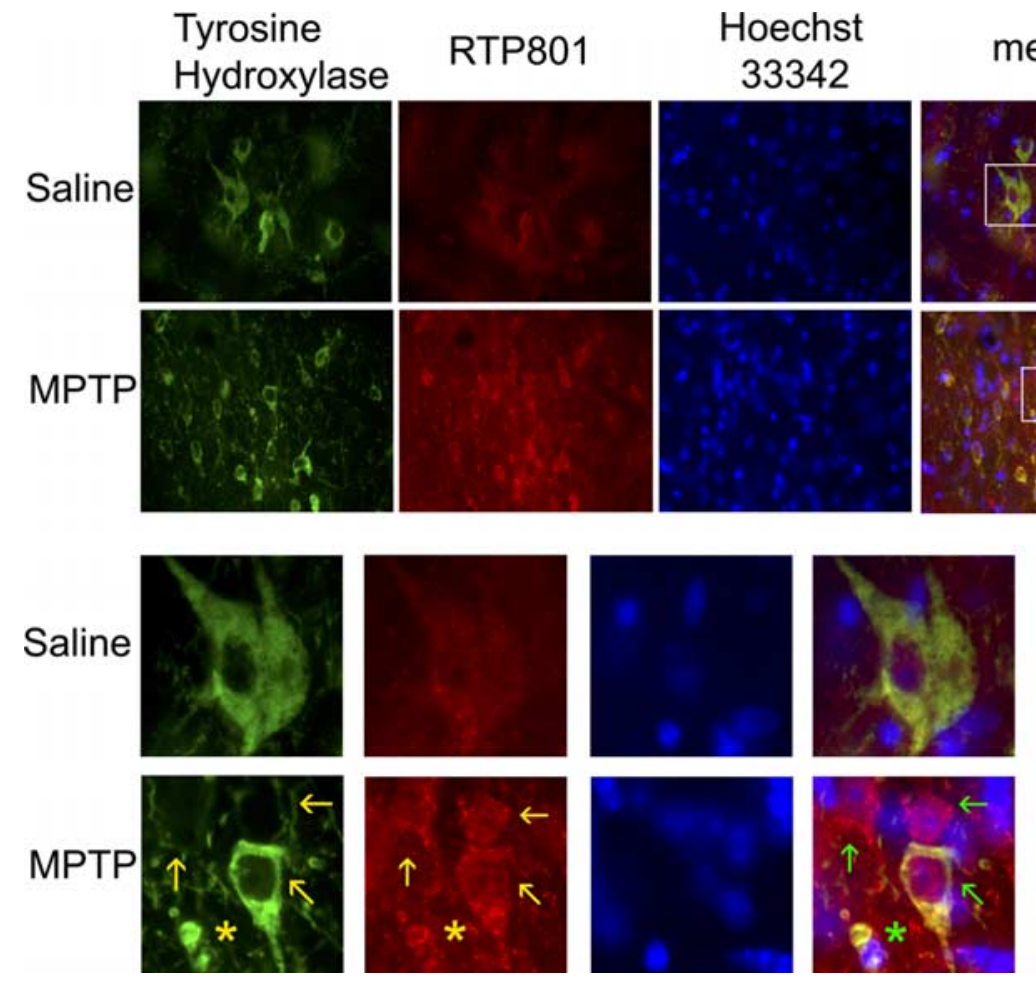

Figure 3. RTP801 expression is induced in the mouse MPTP model of PD. Sections containing the substantia nigra of mice $24 \mathrm{~h}$ after treatment with either saline (as controls) or MPTP were immunostained for tyrosine hydroxylase (green) and RTP801 (red). Sections were also stained with Hoechst 33342 to visualize nuclei (blue). The top row shows a low-power view. The bottom row shows an enlargement of the area within the white frames. Arrowheads show three RTP801-stained cells with neuron-like morphology, one of which is positive for TH. The asterisk shows a cell that is positive for both TH and RTP801 that appears to be in an advanced state of degeneration.
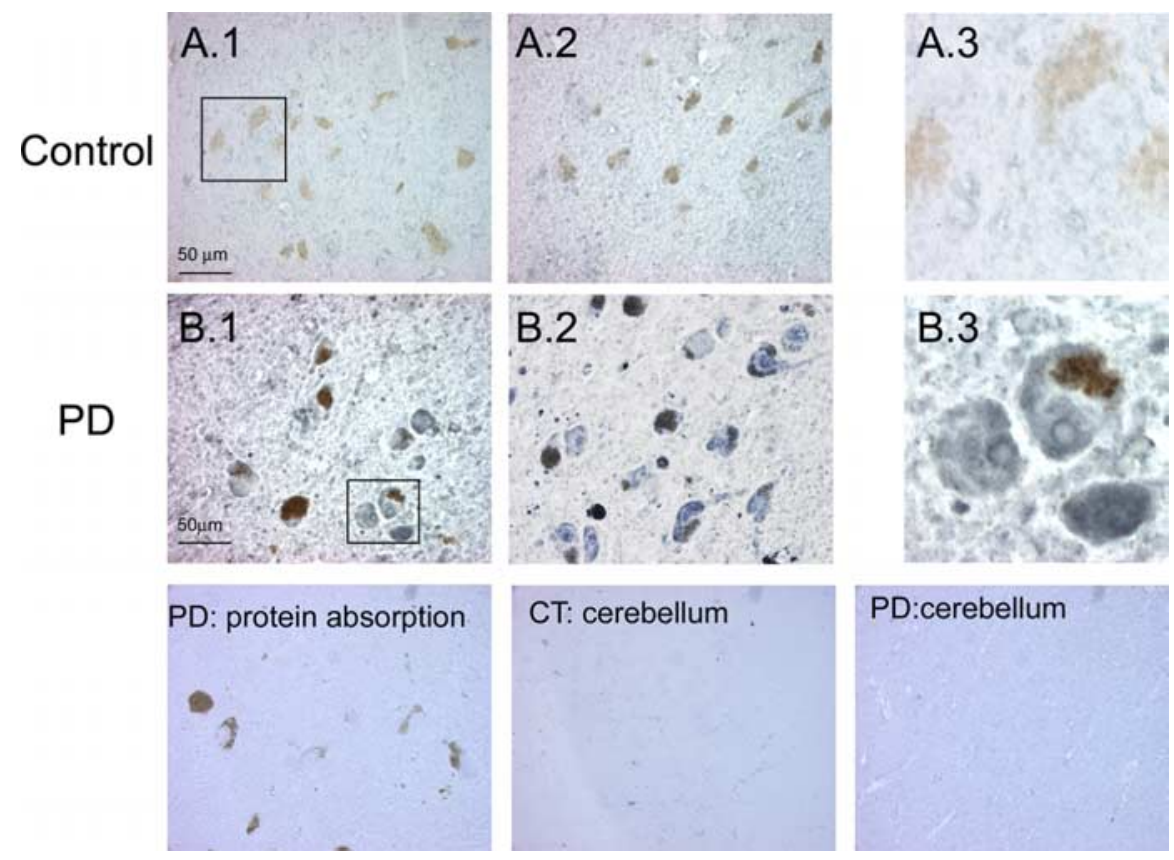

Figure 4. RTP801 expression is elevated in human PD substantia nigral neurons. $A, B$, Sections of postmortem human SN from control $(\boldsymbol{A}$. 1, $\boldsymbol{A}$.2) and PD $(\boldsymbol{B}$.1, B.2) brains were immunostained (blue) for RTP801. Note the presence of neuromelanin granules (brown) in the somas of dopaminergic neurons. $\boldsymbol{A . 3}$ and $\boldsymbol{B} .3$ show enlargement of areas depicted in the boxes of $\boldsymbol{A . 1}$ and $\boldsymbol{B . 1}$, respectively. PD: protein absorption, Substantia nigral sections from the same case as shown in $\boldsymbol{B}$ were stained with RTP801 antiserum preabsorbed with the RTP801 fusion protein used to generate the antiserum. CT: cerebellum, PD: cerebellum, Sections of cerebellum from the same control and PD brains, respectively, were immunostained under the same conditions with anti-RTP801. 


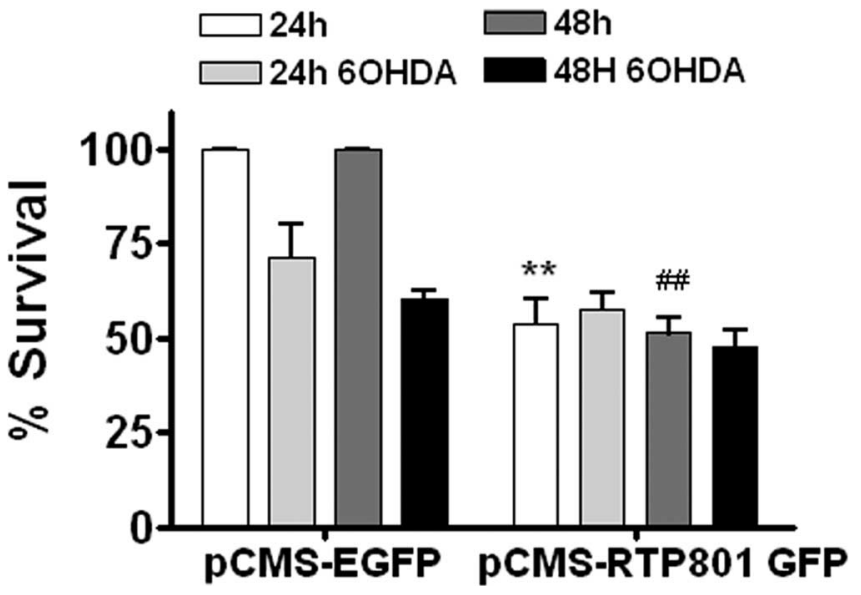

Figure 5. RTP801 overexpression induces cell death of neuronal PC12 cells but does not synergize with 6-OHDA. Neuronal PC12 cells were transfected with pCMS- eGFP or pCMSeGFP-RTP801 and then treated $2 \mathrm{~d}$ later with or without $100 \mu \mathrm{m}$ 6-OHDA. Transfected (eGFP ${ }^{+}$) surviving cells were counted under fluorescence microscopy at $24 \mathrm{~h}$ (light gray bars) or $48 \mathrm{~h}$ (black bars) of 6-OHDA or mock control exposure. Values represent mean \pm SEM for three independent experiments done in triplicate. ${ }^{* *} p<0.05$ versus 24 h eGFP ${ }^{+}$control cells; ${ }^{\# \#} p<$ 0.05 versus $48 \mathrm{~h} \mathrm{eGFP}^{+}$control cells.

A

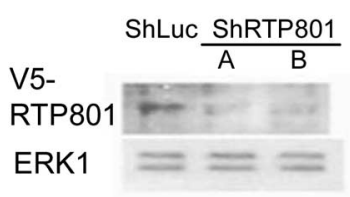

B

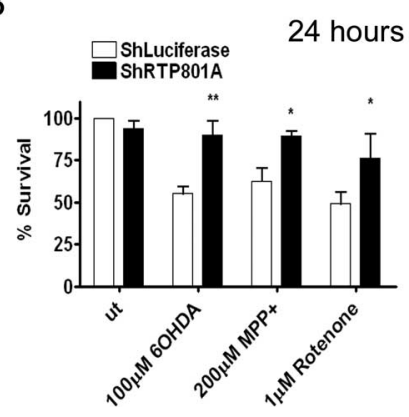

C
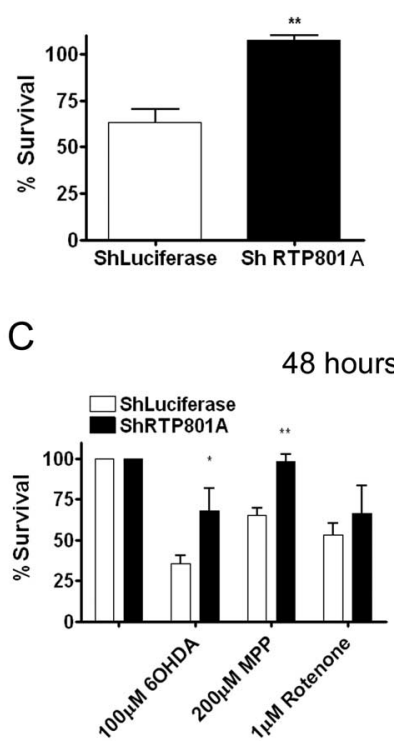

Figure 6. RTP801 mediates cell death in cellular models of PD. A, pSIREN-shRTP801A and pSIREN-shRTP801B knockdown RTP801 protein expression. HEK293 cells were cotransfected with the RTP801-V5-tagged construct and with pSIREN-shRTP801A or pSIREN-shRTP801B or, as control, pSIREN-shLuciferase. Two days later, cell extracts were prepared and subjected to Western immunoblotting with anti-V5 antibody (top). The same membrane was reprobed with anti-ERK1 antibody as a protein loading control (bottom). B, C, Knockdown of RTP801 protects neuronal PC12 cells from PD mimetics. Neuronal PC12 cells were transfected with PSIRENshRTP801A and, as a control, with a pSIREN-shRNA against luciferase. Two days after transfection, cultures were exposed to $100 \mu \mathrm{m}$ 6-OHDA, $200 \mu \mathrm{M} \mathrm{MPP}+$, or $1 \mu \mathrm{m}$ rotenone, and cell survival was assessed by counting surviving transfected cells under fluorescence microscopy after $24 \mathrm{~h}(\boldsymbol{B})$ or $48 \mathrm{~h}(\boldsymbol{C})$. Values are expressed as mean \pm SEM of at least three independent experiments with triplicates in each condition. ${ }^{*} p<0.01$; ${ }^{* *} p<0.001$ compared with cells transfected with pSIREN-shLuciferase. $\boldsymbol{D}$, Rat SCG sympathetic neuron cultures were transfected with pSIREN-shRTP801A or control pSIREN-shRNA against luciferase. Two days later, the cultures were exposed to $5 \mu \mathrm{m}$ 6-OHDA for $24 \mathrm{~h}$, and cell viability was then scored by whole-well counting of transfected cells (DsRed ${ }^{+}$) under fluorescence microscopy. Values are expressed as mean \pm SEM of at least three independent experiments with triplicates in each condition. ${ }^{* *} p<0.001$ compared with cells transfected with shLuciferase. then exposed to a concentration of 6-OHDA ( $5 \mu \mathrm{M})$ that causes $\sim 50 \%$ death. Sympathetic neurons were chosen because they are among those populations that are selectively affected in PD (Koike and Takahashi, 1997; Li et al., 2002). As with neuronal PC12 cells, there was almost total protection of sympathetic neurons from 6-OHDA by shRTP801A (Fig. 6D) and shRTP801B (data not shown) as well as good preservation of morphology. Together, these results indicate that RTP801 plays a required role in neuronal death associated with cellular models of PD.

\section{RTP801 induces cell death in the 6-OHDA model by repressing mTOR through TSC2}

One known action of RTP801 is to inhibit activation of the protein kinase $\mathrm{mTOR}$, an important regulator of cell metabolism and survival that is responsive to various stimuli, including growth factors, cellular energy levels, and stress conditions (Abraham, 2005; Corradetti et al., 2005; Wullschleger et al., 2006). We reasoned that, if RTP801 has such an action in neuronal cells, then its induction by PD mimetics should be accompanied by reduction in mTOR activity. The protein kinase p70S6K is a major substrate for mTOR that phosphorylates it at Ser371, and thus the level of phosphorylation of this site has been a useful indicator of cellular mTOR activity (Saitoh et al., 2002). We verified that inhibition of mTOR activity in neuronal PC12 cells by rapamycin substantially diminished basal phosphorylation of p70S6K at Ser371 (data not shown). We next exposed neuronal PC12 cells to 6-OHDA for different times, and cell extracts were analyzed for mTOR activity by Western immunoblotting with antisera specific for Ser371 p70S6K as well as for total p70S6K and RTP801 (Fig. 8A). This revealed that 6-OHDA triggered a progressive dephosphorylation of p70S6K after the increase in RTP801 protein levels. Thus, the increase in RTP801 triggered by 6-OHDA correlates with a profound reduction in phosphorylation of the MTOR target p70S6K.

We next explored the role of RTP801 in reduction of mTOR activity by 6 -OHDA. Recent findings indicate that mTOR is phosphorylated at Ser2448 by p70S6K and that this is blocked by rapamycin and is therefore dependent on, and hence a measure of, mTOR activity (Chiang and Abraham, 2005). To determine the effect of elevated RTP801 on mTOR activity in our model, we transfected neuronal PC12 cells with pCMS-eGFP or pCMSeGFP-RTP801 and, $24 \mathrm{~h}$ later, monitored the cells for immunostaining with an antibody that specifically recognizes phosphomTOR (Ser2448). Whereas $>90 \%$ of the cells were positive for phospho-mTOR (Ser2448) in control cultures, $<25 \%$ were positive in cells transfected with RTP801 (Fig. 8 B). Exposure of neuronal PC12 cells to 6-OHDA for $1 \mathrm{~d}$ also led to a profound loss of phospho-mTOR (Ser2448) (Fig. 8C). To determine whether this effect was mediated by RTP801, cells were transfected with shRNAs targeted to RTP801 or to an irrelevant protein (luciferase) and evaluated by immunostaining for expression of phospho-mTOR (Ser2448) with or without $1 \mathrm{~d}$ of exposure to 6-OHDA. Both RTP801 shRNAs fully blocked the effect of 6-OHDA on levels of phospho-mTOR (Ser2448) (Fig. 8C). Thus, it appears that mTOR phosphorylation/activity is greatly reduced by 6-OHDA and that this is dependent on RTP801.

We next asked whether interference with the capacity of RTP801 to inhibit mTOR activation would provide protection from 6-OHDA. RTP801 appears to affect mTOR activity by interacting with the tuberous sclerosis complex (which includes the putative chaperone protein TSC1 and the GTPase activating protein TSC2) to inactivate the small G-protein Rheb, which is in turn required for mTOR activation (Garami et al., 2003). To 
suppress RTP801 effects on mTOR activation, we therefore used shRNAs to knock down TSC2 levels. The efficacies of shRNAs against endogenous TSC2 were corroborated by transiently transfecting neuronal PC12 cells with pSIREN-shLuciferase (control) or pSIREN-shTSC2 and, $48 \mathrm{~h}$ later, immunostaining with a TSC2 antibody. Cells transfected with pSIREN-shTSC2 showed little or no staining for TSC2 protein (Fig. 9A, right) (data not shown) compared with cells transfected with pSIREN-shLuciferase (Fig. 9A, left). To test the effect of downregulating TSC2, neuronal PC12 cells were transfected with pSIREN-shTSC2 or pSIREN-shLuciferase and, $48 \mathrm{~h}$ later, were exposed to 6-OHDA. Assessment of surviving transfected $\left(\right.$ DsRed $\left.^{+}\right)$cells revealed that shRNAs targeted to two independent sequences of TSC2 conferred substantial protection against 6-OHDA exposure (Fig. 9B) (data not shown). This observation indicates that TSC2, a protein with which RTP801 interacts to repress mTOR, is essential for cell death in the 6-OHDA model. Finally, to confirm that RTP801 promotes neuron death via TSC2, neuronal PC12 cells were cotransfected with pCMS-eGFP-RTP801 and pSIRENshTSC2. Quantification of surviving cotransfected $\left(\mathrm{GFP}^{+} / \mathrm{DsRed}^{+}\right)$cells 3 d later revealed that abrogation of TSC2 expression by shRNA significantly blocked cell death induced by RTP801 overexpression (Fig. 9C). Similar results were obtained with a shRNA targeted to an independent sequence of TSC2 (data not shown). These findings strongly support the model that RTP801 induced in response to 6-OHDA triggers neuronal death through a mechanism dependent on TSC2 and involving repression of $\mathrm{mTOR}$ activation.

\section{Discussion}

Here we show that RTP801, a novel stressresponsive gene (Ellisen et al., 2002; Shoshani et al., 2002; Wang et al., 2003), is highly and specifically expressed in neuromelanin-positive neurons in the SN of postmortem human PD brains. In contrast, little or no expression was detected in neurons within the same area of control brains or in a nonaffected area (cerebellum) of both PD and control brains. We also show RTP801 induction in substantia nigral neurons in a murine MPTP model of PD. To assess the functional consequences of RTP801 upregulation in catecholaminergic neuronal cells, we used several cellular models of PD. We not only confirmed our previous SAGE-based and Northern blot findings that RTP801 transcripts are induced by the PD mimetic 6-OHDA (Ryu et al., 2005) but showed that this extends to RTP801 protein and to models in which death is triggered by the additional PD mimetics $\mathrm{MPP}+$ and rotenone. We also found that, although RTP801 overexpression is sufficient to promote death of neuronal PC12

\section{ShLuciferase}

merge
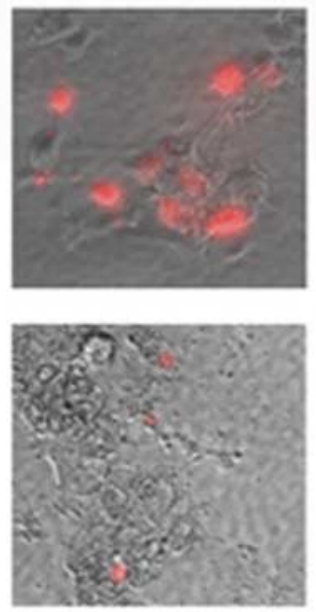

ShRTP801 A
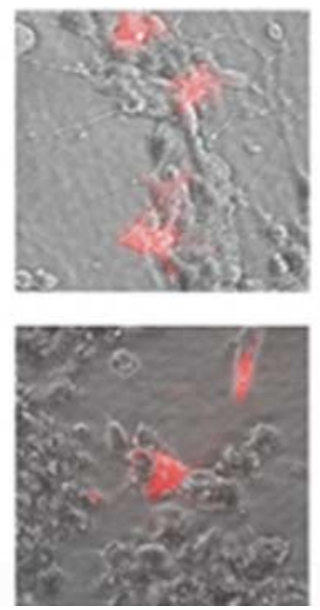
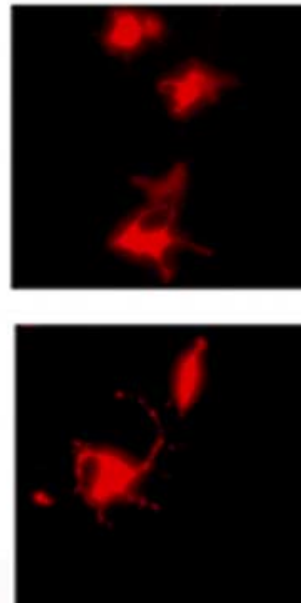
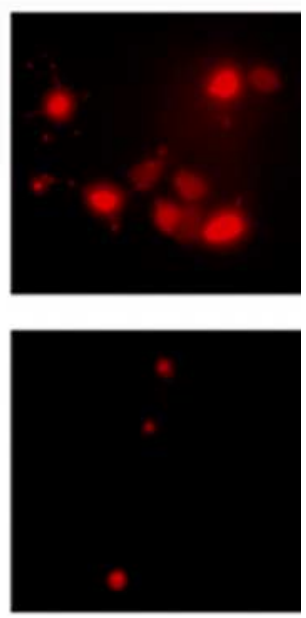

Figure 7. shRTP801 protects neuronal PC12 cells from degeneration and death induced by 6-OHDA. Neuronal PC12 cells were transfected with either pSIREN-shLuciferase (top row) or pSIREN-shRTP801A (bottom row) and $2 \mathrm{~d}$ later were treated with or out $100 \mu \mathrm{m}$ 6-0HDA for $24 \mathrm{~h}$ as indicated. Images were taken of the unfixed cultures under phase contrast or fluorescence and, as revealed by phase contrast, have lost their neurites (compared with untreated cells). In contrast, cells fected with shRTP801 show apparently healthy somas and intact neurites after 6-0HDA exposure. Note that many nontransfected cells in the same phase image were damaged by 6-OHDA.

cells, it does not augment death evoked by 6-OHDA; this suggests that the level of induction achieved by 6-OHDA exposure is maximally efficient in causing cells to die. Significantly, we further observed through the use of shRNAs that RTP801 induction is essential for death evoked by all three PD mimetics in our model system. This effect was not limited to neuronal PC12 cells in that the shRNAs also protected cultured sympathetic neurons (a population affected in PD) from 6-OHDA. Finally, as further addressed below, our findings indicate that, once induced, RTP801 promotes neuron death through interaction with TSC2 and represses activation of the mTOR kinase.

The upregulation of RTP801 in animal and cellular PD models and its selective elevation in vulnerable neurons of postmortem PD patients is highly consistent with known conditions under which RTP801 is induced. These include oxidative and energy 
A

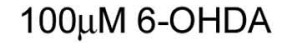

ut 8 h $10 \mathrm{~h} 12 \mathrm{~h} 16 \mathrm{~h} 24 \mathrm{~h}$

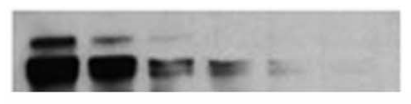

p-(Ser371)

p70S6K

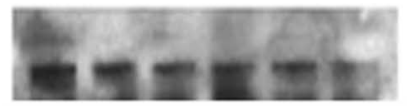

total p70S6K

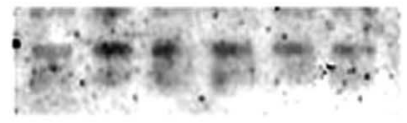

\section{RTP801}

B

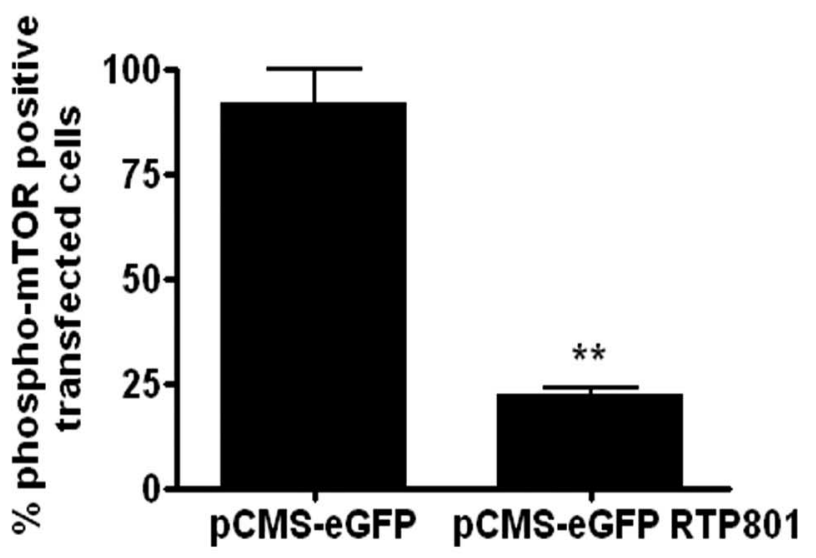

C

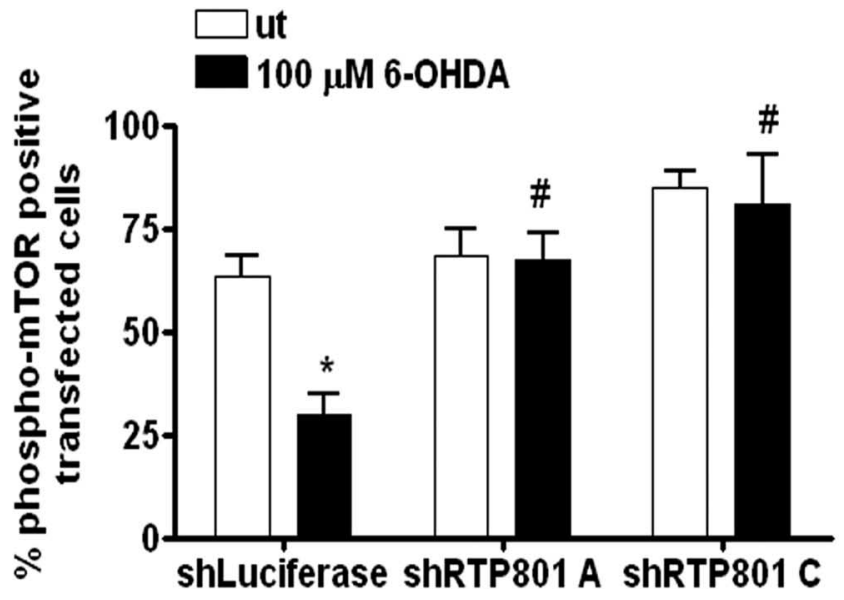

Figure 8. 6-0HDA and RTP801 repress mTOR activity in neuronal PC12 cells. $\boldsymbol{A}$, Phosphorylation of p70S6K1 falls in response to 6-0HDA. Neuronal PC12 cells were exposed to 6-0HDA for the indicated periods of time, and cell extracts were analyzed by Western immunoblotting. Top shows the progressive loss of p70S6K1 phosphorylation using an antibody specific for a phospho-site (Ser371) targeted by mTOR. Membranes were stripped and reprobed for total p70S6K1 protein as well as for RTP801. Note that there is little change in total p70S6K1 levels, whereas there is a dramatic loss of p70S6K1 phosphorylation after elevation of RTP801 levels. $\boldsymbol{B}$, Overexpression of RTP801 induces loss of phospho-mTOR (Ser2448). Neuronal PC12 cells were transfected with pCMS- eGFP or pCMS-eGFP RTP801 and $24 \mathrm{~h}$ later were fixed and stained with the phospho-mTOR (Ser2448) antibody. Proportions of transfected cells (eGFP ${ }^{+}$) positive for expression of phospho-mTOR (Ser2448) were scored per each condition under fluorescence microscopy. Values represent mean \pm SEM for three independent experiments done in triplicate. ${ }^{* *} p<0.05$ for difference with control cells. C, Knocking down RTP801 prevents 6-0HDAinduced loss of phospho-mTOR (Ser2448). Neuronal PC12 cells were transfected with either stress conditions such as hypoxia (Shoshani et al., 2002), arsenite exposure (Lin et al., 2005a), and hydrogen peroxide treatment (Kim et al., 2003). All three PD mimetics used here elicit oxidative stress and energy depletion, in part by interfering with mitochondrial complex I function and electron transport. Moreover, there is increasing evidence linking mitochondrial dysfunction, oxidative stress, and energy depletion to the neurodegeneration that occurs in PD (Dauer and Przedborski, 2003; Dawson and Dawson, 2003; Beal, 2004; Tretter et al., 2004).

Our results with the mouse in vivo MPTP model are consistent with findings obtained for PD mimetics in our cellular models. The vast majority of substantia nigral $\mathrm{TH}^{+}$cells in the sections from MPTP-treated animals were highly stained with RTP801 antiserum. However, there were also some RTP801-positive cells in the SN region that lacked detectable TH expression. In the mouse in vivo model, it has been reported that MPTP induces loss of TH expression within $24 \mathrm{~h}$, even in neurons that still appear viable (Jackson-Lewis et al., 1995). These results are consistent with an early role of RTP801 in mediating degeneration. It is also possible that the decrease in protein translation associated with loss of mTOR activity contributes to the fall in $\mathrm{TH}$ expression.

Although our findings link RTP801 induction to neuron death, it is noteworthy that, in other contexts, this protein is reported to have variable effects on cell survival and that this appears to be dependent on cell type and state as well as apoptotic stimulus. For instance, RTP801 induction in U2OS cells diminished their size but had no reported effect on their survival (Sofer et al., 2005). In HaCaT keratinocytes and HeLa cells, elevated RTP801 protected against UV-induced apoptosis, whereas RTP801 downregulation sensitized the cells to apoptosis (Schwarzer et al., 2005). Similarly, overexpressed RTP801 reduced the sensitivity of WEH17.2 cells to dexamethasoneinduced apoptosis (Wang et al., 2003) and protected MCF7 cells and non-neuronally differentiated PC12 cells from death evoked by hypoxia or $\mathrm{H}_{2} \mathrm{O}_{2}$ (Shoshani et al., 2002) In contrast, RTP801 expression caused death of neuronally differentiated PC12 cells (Shoshani et al., 2002; present findings) and of mouse lung cells in vivo and increased the sensitivity of neuronal PC12 cells to ischemic injury and oxidative stress (Shoshani et al., 2002). Ectopic RTP801 expression also increased the sensitivity of mouse fibroblasts to oxidative stress (Ellisen et al., 2002) and of neuroblastoma cells to $\beta$ amyloid peptide toxicity (Kim et al., 2003). Finally, in a mouse model of retinopathy of prematurity, animals null for RTP801 showed significantly less cell death in the inner nuclear layer (Brafman et al., 2004). Thus, cell- and cell-statespecific cues appear to regulate whether RTP801 exerts proapoptotic or antiapoptotic actions. The limited number of cases currently studied further suggests that, in neurons, RTP801 induction is proapoptotic. This, along with our in vitro and in vivo data, support the idea that elevation of RTP801 in SN neurons increases their susceptibility to death.

In addition to oxidative stress and energy depletion, other proapoptotic stimuli are reported to induce RTP801, including DNA damage (Ellisen et al., 2002; Lin et al., 2005b) and dexamethasone exposure (Wang et al., 2003). Accordingly, we noted

pSIREN-shLuciferase or pSIREN-shRTP801A or ShRTP801C and $2 \mathrm{~d}$ later were treated with or without $100 \mu \mathrm{m}$ 6-OHDA for $24 \mathrm{~h}$. Then cells were immunostained with the phospho-mTOR (Ser2448) antibody. Proportions of transfected cells positive for phospho-mTOR (Ser2448) were scored as in $\boldsymbol{B}$. Values represent mean \pm SEM for three independent experiments done in triplicate. ${ }^{*} p<0.01$ versus untreated shLuciferase-transfected cells; ${ }^{\#} p<0.01$ versus 6-OHDA-treated shLuciferase-transfected cells. ut, Untreated. 
that RTP801 was elevated in neuronal PC12 cells exposed to the DNA-damaging agent camptothecin. However, RTP801 downregulation was not protective, indicating that, in this case, alternative pathways can mediate death. Our findings also indicate that RTP801 is not elevated under all apoptotic conditions. For instance, NGF deprivation, a potent apoptotic stimulus in our cultures, did not detectably induce RTP801, and there was no protection by shRTP801.

With respect to the mechanism of RTP801 action, most studies thus far have been in the context of stress responses and their effects on cancer cell growth control and survival. These have pointed to $\mathrm{mTOR}$, a key positive regulator of protein synthesis, cell growth, proliferation, and survival (Fingar and Blenis, 2004). Activation of mTOR requires the GTP-charged form of the small G-protein Rheb, which binds to its kinase domain. The tuberous sclerosis complex (TSC1/2) is an upstream negative regulator of $\mathrm{mTOR}$ activation because TSC2, in association with the chaperone TSC1, has GAP (GTPase-activating protein) activity for Rheb (Long et al., 2005; Wullschleger et al., 2006). In tumor growth-associated hypoxia, RTP801 has been reported to act via TSC1/TSC2 to inhibit activation of mTOR kinase (Brugarolas et al., 2004; Corradetti et al., 2005).

Our observations are consistent with the above studies and indicate that death evoked by 6-OHDA and RTP801 require TSC2. This, in turn, suggests that inactivation of mTOR as a key element in the mechanism by which 6-OHDA and RTP801 induce neuronal death. Exposure of neuronal PC12 cells to 6-OHDA triggered a progressive reduction in cellular mTOR activity, as indicated by p70S6K1 and mTOR dephosphorylation. This occurred in parallel with RTP801 upregulation. Previous work has shown that RTP801 inhibits mTOR activation and promotes dephosphorylation of p70S6K1 (Brugarolas et al., 2004). These events were visible 8-10 h after 6-OHDA exposure and commenced before the appearance (and thus were not a consequence) of cell death. Furthermore, interference with TSC2 expression with shRNAs protected against 6-OHDA exposure as well as against overexpressed RTP801.

Recently, an additional function of Rheb has been described, apart from mTOR activation. Activated Rheb interacts with and inhibits Raf kinase in a rapamycin-insensitive manner in HEK293 cells (Karbowniczek et al., 2006). Thus, it is possible that RTP801 affects neuron survival via Rheb inactivation by mechanisms in addition to suppression of mTOR activity.

The mechanisms by which RTP801-mediated suppression of mTOR activity might lead to neuron death are presently unclear. Rapamycin, a drug that inhibits certain actions of mTOR, including phosphorylation of p70S6K, does not trigger death of neuronal PC12 cells (Powers et al., 1999) (C. Malagelada, unpublished data). This suggests that the critical pathway by which RTP801 evokes death does not involve rapamycin-sensitive actions of mTOR. Rapamycin-insensitive actions of mTOR have been described recently (Jacinto et al., 2004; Sarbassov et al., 2004), and it will be important to consider their potential role in neuron survival and PD.

In summary, we find that the recently described stressresponsive gene RTP801 is induced in cellular models of PD and is an essential mediator of death in these systems. RTP801 appears to trigger death through interaction with TSC2 and represses activation of the mTOR kinase. Moreover, RTP801 expression is elevated in substantia nigral neurons of both MPTP-treated mice and postmortem human PD brains. Together, these observations suggest that RTP801 and the molecular pathways in which it functions may play significant roles in neurodegeneration associated with PD and are possible targets for therapeutic intervention. Because RTP801 is induced by oxidative and energy stress, it may well be involved in additional neurodegenerative diseases and neuronal disorders in which such stresses occur. Finally, it is noteworthy that our interest in RTP801 in the context of PD arose from a SAGE study of cultured neural cells. This reinforces the potential of reductionist approaches to study neurodegenerative disorders. 


\section{References}

Abraham RT (2005) TOR signaling: an odyssey from cellular stress to the cell growth machinery. Curr Biol 15:R139-R141.

Beal MF (2004) Mitochondrial dysfunction and oxidative damage in Alzheimer's and Parkinson's diseases and coenzyme Q10 as a potential treatment. J Bioenerg Biomembr 36:381-386.

Biswas SC, Ryu E, Park C, Malagelada C, Greene LA (2005) Puma and p53 play required roles in death evoked in a cellular model of Parkinson disease. Neurochemical Res 30:839-845.

Blum D, Wu Y, Nissou MF, Arnaud S, Alim Louis B, Verna JM (1997) p53 and Bax activation in 6-hydroxydopamine-induced apoptosis in PC12 cells. Brain Res 751:139-142.

Blum D, Torch S, Lambeng N, Nissou M, Benabid AL, Sadoul R, Verna JM (2001) Molecular pathways involved in the neurotoxicity of 6-OHDA, dopamine and MPTP: contribution to the apoptotic theory in Parkinson's disease. Prog Neurobiol 65:135-172.

Brafman A, Mett I, Shafir M, Gottlieb H, Damari G, Gozlan-Kelner S, Vishnevskia-Dai V, Skaliter R, Einat P, Faerman A, Feinstein E, Shoshani $\mathrm{T}$ (2004) Inhibition of oxygen-induced retinopathy in RTP801deficient mice. Invest Ophthalmol Vis Sci 45:3796-3805.

Brugarolas J, Lei K, Hurley RL, Manning BD, Reiling JH, Hafen E, Witters LA, Ellisen LW, Kaelin Jr WG (2004) Regulation of mTOR function in response to hypoxia by REDD1 and the TSC1/TSC2 tumor suppressor complex. Genes Dev 18:2893-2904.

Chiang GG, Abraham RT (2005) Phosphorylation of mammalian target of rapamycin (mTOR) at Ser-2448 is mediated by p70S6 kinase. J Biol Chem 280:25485-25490

Corradetti MN, Inoki K, Guan KL (2005) The stress-inducted proteins RTP801 and RTP801L are negative regulators of the mammalian target of rapamycin pathway. J Biol Chem 280:9769-9772.

Dauer W, Przedborski S (2003) Parkinson's disease: mechanisms and models. Neuron 39:889-909.

Davis GC, Williams AC, Markey SP, Ebert MH, Caine ED, Reichert CM, Kopin IJ (1979) Chronic Parkinsonism secondary to intravenous injection of meperidine analogues. Psychiatry Res 1:249-254.

Dawson TM, Dawson VL (2003) Molecular pathways of neurodegeneration in Parkinson's disease. Science 302:819-822.

Ellisen LW, Ramsayer KD, Johannessen CM, Yang A, Beppu H, Minda K, Oliner JD, McKeon F, Haber DA (2002) REDD1, a developmentally regulated transcriptional target of p63 and p53, links p63 to regulation of reactive oxygen species. Mol Cell 10:995-1005.

Fahn S (1998) Medical treatment of Parkinson's disease. J Neurol 245:P15-P24.

Fingar DC, Blenis J (2004) Target of rapamycin (TOR): an integrator of nutrient and growth factor signals and coordinator of cell growth and cell cycle progression. Oncogene 23:3151-3171.

Frolov A, Chahwan S, Ochs M, Arnoletti JP, Pan ZZ, Favorova O, Fletcher J, von Mehren M, Eisenberg B, Godwin AK (2003) Response markers and the molecular mechanisms of action of Gleevec in gastrointestinal stromal tumors. Mol Cancer Ther 2:699-709.

Garami A, Zwartkruis FJ, Nobukuni T, Joaquin M, Roccio M, Stocker H, Kozma SC, Hafen E, Bos JL, Thomas G (2003) Insulin activation of Rheb, a mediator of mTOR/S6K/4E-BP signaling, is inhibited by TSC1 and 2. Mol Cell 11:1457-1466.

Gorell JM, Johnson CC, Rybicki BA, Peterson EL, Richardson RJ (1998) The risk of Parkinson's disease with exposure to pesticides, farming, well water, and rural living. Neurology 50:1346-1350.

Greene LA, Tischler AS (1976) Establishment of a noradrenergic clonal line of rat adrenal pheochromocytoma cells which respond to nerve growth factor. Proc Natl Acad Sci USA 73:2424-2428.

Hughes AJ, Daniel SE, Blankson S, Lees AJ (1993) A clinicopathologic study of 100 cases of Parkinson's disease. Arch Neurol 50:140-148.

Jacinto E, Loewith R, Schmidt A, Lin S, Ruegg MA, Hall A, Hall MN (2004) Mammalian TOR complex 2 controls the actin cytoskeleton and is rapamycin insensitive. Nat Cell Biol 6:1122-1128.

Jackson-Lewis V, Jakowec M, Burke RE, Przedborski S (1995) Time course and morphology of dopaminergic neuronal death caused by the neurotoxin 1-methyl-4-phenyl-1,2,3,6-tetrahydropyridine. Neurodegeneration 4:257-269.

Karbowniczek M, Robertson GP, Henske EP (2006) Rheb inhibits C-Raf activity and B-Raf/C-Raf heterodimerization. J Biol Chem 281:25447-25456.
Kim JR, Lee SR, Chung HJ, Kim S, Baek SH, Kim JH, Kim YS (2003) Identification of amyloid beta-peptide responsive genes by cDNA microarray technology: involvement of RTP801 in amyloid beta-peptide toxicity. Exp Mol Med 35:403-411.

Koike Y, Takahashi A (1997) Autonomic dysfunction in Parkinson's disease. Eur Neurol 38 [Suppl 2]:8-12.

Li ST, Dendi R, Holmes C, Goldstein DS (2002) Progressive loss of cardiac sympathetic innervation in Parkinson's disease. Ann Neurol 52:220-223.

Lin L, Stringfield TM, Shi X, Chen Y (2005a) Arsenite induces a cell stress response gene RTP801 through reactive oxygen species and transcription factors Elk-1 and CCAAT/enhancer binding protein. Biochem J 392:93-102.

Lin L, Qian Y, Shi X, Chen Y (2005b) Induction of a cell stress response gene RTP801 by DNA damaging agent methyl methanesulfonate through CCAAT/enhancer binding protein. Biochemistry 44:3909-3914.

Long X, Lin Y, Ortiz-Vega S, Yonezawa K, Avruch J (2005) Rheb binds and regulates the mTOR kinase. Curr Biol 15:702-713.

Powers JF, Tischler AS, Cherington V (1999) Discordant effects of rapamycin on proliferation and p70S6 kinase phosphorylation in normal and neoplastic rat chromaffin cells. Neurosci Lett 259:137-140.

Rukenstein A, Rydel RE, Greene LA (1991) Multiple agents rescue PC12 cells from serum-free cell death by translation- and transcriptionindependent mechanisms. J Neurosci 11:2552-2563.

Ryu EJ, Harding HP, Angelastro JM, Vitolo OV, Ron D, Greene LA (2002) Endoplasmic reticulum stress and the unfolded protein response in cellular models of Parkinson's disease. J Neurosci 22:10690-10698.

Ryu EJ, Angelastro JM, Greene LA (2005) Analysis of gene expression changes in a cellular model of Parkinson disease. Neurobiol Dis 18:54-74.

Saitoh M, Pullen N, Brennan P, Cantrell D, Dennis PB, Thomas G (2002) Regulation of an activated S6 kinase 1 variant reveals a novel mammalian target of rapamycin phosphorylation site. J Biol Chem 277:20104-20112.

Sarbassov DD, Ali SM, Kim DH, Guertin DA, Latek RR, Erdjument-Bromage H, Tempst P, Sabatini DM (2004) Rictor, a novel binding partner of $\mathrm{mTOR}$, defines a rapamycin-insensitive and raptor-independent pathway that regulates the cytoskeleton. Curr Biol 14:1296-1302.

Schwarzer R, Tondera D, Arnold W, Giese K, Klippel A, Kaufmann J (2005) REDD1 integrates hypoxia-mediated survival signaling downstream of phosphatidylinositol 3-kinase. Oncogene 24:1138-1149.

Sherer TB, Betarbet R, Testa CM, Seo BB, Richardson JR, Kim JH, Miller GW, Yagi T, Matsuno-Yagi A, Greenamyre JT (2003) Mechanism of toxicity in rotenone models of Parkinson's disease. J Neurosci 23:10756-10764.

Shoshani T, Faerman A, Mett I, Zelin E, Tenne T, Gorodin S, Moshel Y, Elbaz S, Budanov A, Chajut A, Kalinski H, Kamer I, Rozen A, Mor O, Keshet E, Leshkowitz D, Einat P, Skaliter R, Feinstein E (2002) Identification of a novel hypoxia-inducible factor 1-responsive gene, RTP801, involved in apoptosis. Mol Cell Biol 22:2283-2293.

Sofer A, Lei K, Johannessen CM, Ellisen LW (2005) Regulation of mTOR and cell growth in response to energy stress by REDD1. Mol Cell Biol 25:5834-5845.

Thoenen H, Tranzer JP (1968) Chemical sympathectomy by selective destruction of adrenergic nerve endings with 6-Hydroxydopamine. Naunyn Schmiedebergs Arch Pharmacol 261:271-288.

Tretter L, Sipos I, Adam-Vizi V (2004) Initiation of neuronal damage by complex I deficiency and oxidative stress in Parkinson's disease. Neurochem Res 29:569-577.

Troy CM, Rabacchi SA, Friedman WJ, Frappier TF, Brown K, Shelanski ML (2000) Caspase- 2 mediates neuronal cell death induced by $\beta$-amyloid. J Neurosci 20:1386-1392.

Walkinshaw G, Waters CM (1994) Neurotoxin-induced cell death in neuronal PC12 cells is mediated by induction of apoptosis. Neuroscience 63:975-987.

Wang Z, Malone MH, Thomenius MJ, Zhong F, Xu F, Distelhorst CW (2003) Dexamethasone-induced gene 2 (dig2) is a novel pro-survival stress gene induced rapidly by diverse apoptotic signals. J Biol Chem 278:27053-27058.

Wullschleger S, Loewith R, Hall MN (2006) TOR signaling in growth and metabolism. Cell 124:471-484.

Xu Z, Maroney AC, Dobrzanski P, Kukekov NV, Greene LA (2001) The MLK family mediates c-Jun N-terminal kinase activation in neuronal apoptosis. Mol Cell Biol 21:4713-4724.

Yan CY, Greene LA (1998) Prevention of PC12 cell death by $\mathrm{N}$-acetylcysteine requires activation of the Ras pathway. J Neurosci 18 4042-4049. 